\title{
The therapeutic hypothermia after resuscitated cardiac arrest caused by ventricular fibrillation: a retrospective study in Saint Pierre University Hospital
}

\author{
Séverine Libert ${ }^{1}$, Pierre Mols ${ }^{1}$, Philippe Dechamps ${ }^{2}$, Marc Claus ${ }^{2}$, Christian Mélot ${ }^{3}$, Benoit \\ Claessens $^{1}$
}

1. Emergency Department, Centre Hospitalier Universitaire Saint Pierre (ULB), Bruxelles, Belgium. 2. Intensive Care Unit, Centre Hospitalier Universitaire Saint Pierre (ULB), Bruxelles, Belgium. 3. Emergency Department, Erasme University Hospital (ULB), Brussels, Belgium.

Correspondence: Séverine Libert. Address: Rue de Trazegnies 187 - 6180 Courcelles - Belgium. E-mail: sev.libert@hotmail.com

Received: January 5, 2014

Accepted: February 27, 2014

Online Published: March 21, 2014

DOI : $10.5430 /$ jha.v3n4p82

URL: http://dx.doi.org/10.5430/jha.v3n4p82

\section{Abstract}

Background: Therapeutic hypothermia is recommended as soon as possible for the neurological protection of comatose patients after cardiorespiratory arrest (CA) caused by pulseless ventricular fibrillation (VF) or tachychardia (VT). This retrospective study evaluates the adherence to the hypothermia protocol in Emergency Department and Intensive Care Units of Saint Pierre University Hospital (SPUH).

Methods: Retrospective analyses of the database records from the 1st January 2005 to the 31st December 2010 concerning all the out-of-hospital arrests due to ventricular fibrillation admitted alive in the hospital. Transferred or NTBR patients were excluded.

Results: Of the 72 patients studied, $68 \%$ were discharged alive from the hospital, of which $84 \%$ were free of neurological sequelae. Hypothermia was used in 44 patients, unjustified in 5 cases. There were also 5 cases for which it was needed, but not applied. Hypothermia $\left(32^{\circ} \mathrm{C}-34^{\circ} \mathrm{C}\right)$ was achieved in a median time of 9.5 hours (range: 1.5 hours -39 hours) and lasted a median 21 hours (range: 7 hours -31 hours). Hypothermic patient survival was $72.7 \%$, with $81 \%$ good neurological outcome.

Conclusion: The protocol application in our small study gives as good figures as previous studies. Few errors of inclusion and exclusion are still present. Implementation of a common protocol for Emergency Medical Service (EMS), Emergency Department (ED) and Intensive Care Unit (ICU) would shorten the time to obtain the target temperature. The creation and implementation of a specific register with CA patients who received hypothermia would lead to a better medical follow-up for the patient and improve the current knowledge related to this technique.

\section{Key words}

Out-of-hospital cardiac arrest, Ventricular fibrillation, Therapeutic hypothermia, Neurological and survival outcomes 


\section{I ntroduction}

Each year about ten thousand cardiac arrests (CA) are reported in Belgium ${ }^{[1]}$. These cardiac arrests are included in a group of diseases for which the Federal Public Service of Health requires a recording by each hospital. This recording was based on the recommendations published by the European Communities about medical emergency. It highlights the importance of an organized care system during the first hour of management for five acute and frequent pathologies. This "first hour" quintet includes cardiorespiratory arrest, stroke, myocardial infarction, severe multiple trauma and acute respiratory insufficiency. Belgian authorities added suicide attempts, given their frequency in the country ${ }^{[2]}$.

Although CA has long been researched, the survival rate of CA patients is improving very slowly. The positive impact on the survival rate of CA patients has been demonstrated only for two interventions. First, CA victims need early cardiac massage. Bystander-initiated cardiopulmonary resuscitation (B-CPR) can double survival rates ${ }^{[3]}$. When the rhythm is ventricular fibrillation (VF), it is necessary to shock as soon as possible. Each passing minute without defibrillation decreases the chances of survival by $7 \%$ to $10 \%{ }^{[4]}$. One study in Brussels showed threefold increase in VF survival when an automatic external defibrillator (AED) was used outside the hospital ${ }^{[5]}$. More recently, the neurological outcome of survivors of VF CA was shown to be improved using therapeutic hypothermia ${ }^{[6-8]}$. So, these three points form the uncontested current basis of CA initial management.

As mentioned previously, the two first items were already the subject of numerous publications. In 1990, Cummins described the chain of survival corresponding to the sequence of the pre-hospital actions that improved CA patient survival and outcome: emergency calls, cardiac massage, external defibrillation, and post- resuscitation care ${ }^{[9]}$. Since the International Liaison Committee on Resuscitation (ILCOR) creation, research in this field was developed and recommendations are published every five years in order to optimize CA patient management, survival and neurological outcome. Thus, it is necessary to improve CPR: chest compressions must be quicker and deeper, compressions should be interrupted for as short a time as possible and only for emergent issues, the AED should be used and emergency call should be made as soon as possible ${ }^{[10]}$.

In the meantime, therapeutic hypothermia has been included in international recommendations since 2003, following two New England Journal of Medicine publications ${ }^{[6,7]}$. This mild therapeutic hypothermia, targeted between $32^{\circ} \mathrm{C}$ and $34^{\circ} \mathrm{C}$, must last 12 hours -24 hours ${ }^{[1,4,6,7]}$. Many studies showed a beneficial neurologic outcome of hypothermia closely related to its neuroprotective effect. It increased survival without major neurological sequelae for comatose patients after a CA following a ventricular fibrillation or tachycardia resuscitated successfully ${ }^{[6,7,11]}$. In this context, a protocol for cerebral protection by hypothermia after CA was introduced in the Intensive Care Unit (ICU) of Saint-Pierre University Hospital in 2004 and was updated regularly.

The physiological mechanism for the neurological damage associated with CA remains unclear. Cardiac ischemia producing low-flow neurological state would result in a decrease in cerebral metabolic rate for glycogen and glucose, an increase of lactate production, a decrease of the phosphocreatine and ATP production, and a tissue acidosis. Furthermore, during the cerebral reperfusion, increased intracellular glutamate (neuroexcitatory amino-acid) would start a cascade leading to reactive oxygen species accumulation and activation of enzymes, both harmful for cerebral tissues. The decrease in body temperature would protect against all this in various ways: the decreased oxygen requirement would protect against a probable ischemia, the reduced activation of pathological cascades and the inhibition of the mediators' biosynthesis and their release would lead to a lower rate of free radicals and enzymes lower rate. Finally an intracranial pressure reduction (creating an increased blood flow and thus, a reconstruction of the cerebral microcirculation) was also observed $^{[8-10,12]}$.

In this work, we focus on the application of the recommendations relative to hypothermia in Saint Pierre University Hospital's (SPUH's) ICU: the delay for reaching the temperature target, the depth and duration of therapeutic hypothermia as well as the inclusion and exclusion criteria in the protocol. Group characteristics and post-hypothermia survival and neurological outcome were also investigated, as well as thermal fluctuations. 


\section{Patients and methods}

From January 1st 2005 to December 31th 2010, the data were collected through the ICD9-CM codes assigned to CA patients admitted in SPUH. Then, patients who died on the arrival at the hospital, those with unknown first cardiac rhythm (CR), patients transferred from other hospitals, those with NTBR orders (not to be resuscitated), and with pulseless electrical activity (PEA) were excluded. Finally, patients with out-of-hospital CA with VF as the first CR were selected (see Figure 1).

Figure 1. Flow chart for the selected patients

Note. Criteria of inclusion: extra-hospital cardiac arrests taken in charge by the Saint Pierre University Hospital between January 1st 2005 and 31st December 2010, with ventricular fibrillation (VF) as the first cardiac rhythm (CR), alive at the hospital admission. Criteria of exclusion: transferred patients, not to be resuscitated (NTBR), pulseless electrical activity (PEA).

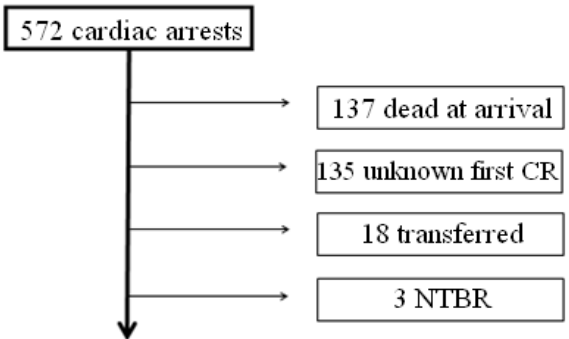

279 with first $C R$

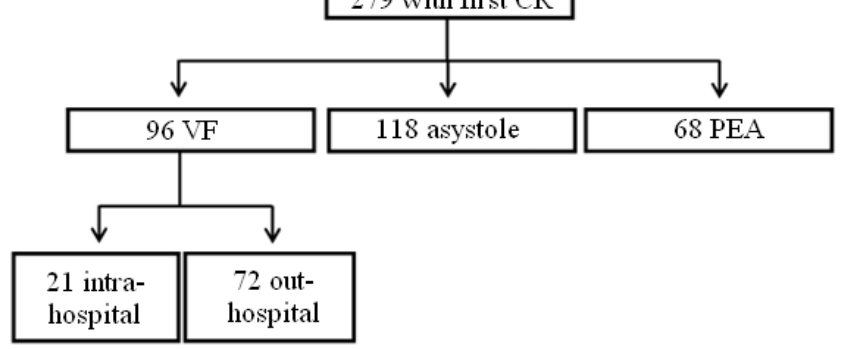

Age, gender, etiology and location of the CA, presence of a bystander or not, use of an AED outside the hospital were recorded. The first time temperature, survival and neurological outcome at various times points were also recorded.

In accordance with the SPUH's hypothermia protocol, any patient with recovery of a spontaneous circulation (ROSC) after a CA and not responding to simple commands was included. Dying patients, those with a cerebral hemorrhage, a major shock requiring high levels of vasopressors, or a severe bleeding leading to hemorrhagic shock were excluded. The temperature was measured by intravascular thermistor or intra-rectal probe. Patients included in this protocol were sedated and curarized if necessary. Saline $0.9 \%$ solution were given upon arrival in the emergency department (ED), and ice-bags were placed around at the neck. Once in ICU, the patient was placed on a cooling mattress with a cap on the head to reach target temperature between $32^{\circ} \mathrm{C}-34^{\circ} \mathrm{C}$. The time needed to reach the target and the duration of hypothermia were recorded.

Given the low number of patients, no statistical comparison was made. The continuous data were tested for normality using the Shapiro-Wilk test and were reported either as mean \pm standard deviation either in median (range: minimum maximum). The categorical data were reported as percentages.

\section{Results}

Over the five past years, the ED and the ICU treated 72 patients with an out-of-hospital CA with VF as initial rhythm. The population was on average 60 years-old, 52 men and 20 women. CPR was started by a bystander in 20 patients (27.8\%). An AED was used outside the hospital in 62 patients (86.1\%). The causes of CA were divided between $93.1 \%$ of suspected cardiac origin (among which $83 \%$ were certified) and $6.9 \%$ of miscellaneous origin (pulmonary, ionic disturbance, drug intoxication). One third of the group died (31.9\%), one third returned to home $(31.9 \%)$ and the remaining third was transferred to another hospital (36.2\%) for additional and/or rehabilitation treatment (see Table 1). 
Table 1. Demographic and clinical characteristics of patients admitted in the Intensive Care Unit, having presented an out-of-hospital cardiac arrest due to ventricular fibrillation

\begin{tabular}{ll}
\hline Item & result \\
\hline Age, years & $60 \pm 2$ \\
Men/Women & $52 / 20$ \\
CPR started by bystander, n (\%) & $20(27.8 \%)$ \\
Out-of-hospital AED, n (\%) & $62(86.1 \%)$ \\
Initial place of CA: & \\
$\quad$ Home, n (\%) & $28(38.9 \%)$ \\
$\quad$ Public, $\mathrm{n}(\%)$ & $23(31.9 \%)$ \\
$\quad$ Unknown, $\mathrm{( \% )}$ & $21(29.2 \%)$ \\
Etiology : & $67(93.1 \%)$ \\
$\quad$ Cardiac supposed & $5(6.9 \%)$ \\
Other & \\
At the discharge from the hospital: & $23(31.9 \%)$ \\
$\quad$ Death, $\mathrm{n}(\%)$ & $23(31.9 \%)$ \\
Back to home, $\mathrm{n}(\%)$ & $26(36.2 \%)$ \\
Transfer to another institution, $\mathrm{n}(\%)$ & \\
\hline
\end{tabular}

Among the entire study group, 53 patients did not respond to a simple command after ROSC. Only 39 were included hypothermia protocol. The reasons not to cool were variable: eight patients had hemodynamic instability, one patient had respiratory instability (severe hypoxemia), two patients showed metabolic derangement or a drug intoxication which were judged as contra-indications to cooling, and three patients did not benefit whereas it was recommended. On the other hand, five patients with a neurological state considered as normal were cooled whereas it was not indicated, and that without justification in medical records (see Table 2).

Table 2. Distribution of cooled and not cooled patients according to their neurological status and their own particular medical characteristics

\begin{tabular}{|c|c|c|c|c|c|}
\hline & \multicolumn{4}{|c|}{ Alteration of neurological status } & \multirow{2}{*}{$\begin{array}{l}\text { Normal } \\
\text { neurological } \\
\text { status }\end{array}$} \\
\hline & Hemodynamic stability & $\begin{array}{l}\text { Hemodynamic and } \\
\text { pulmonary instability }\end{array}$ & $\begin{array}{l}\text { Ionic disturbance } \\
\text { and drug overdose }\end{array}$ & Unknown & \\
\hline Cooled patients & 39 & 0 & 0 & 0 & 5 \\
\hline Not cooled patients & 0 & 9 & 2 & 3 & 14 \\
\hline
\end{tabular}

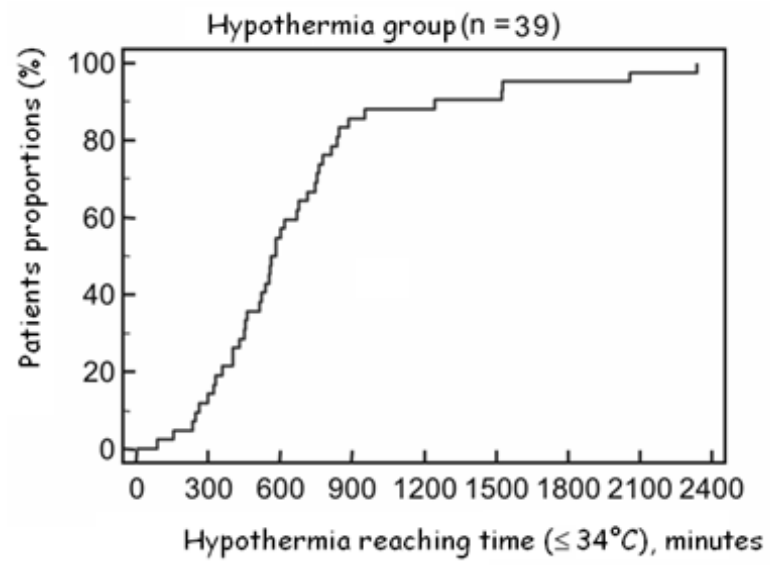

Figure 2. Curve of hypothermia reaching time 
When hypothermia was initiated, it took a median time of 9.5 hours (range: 1.5 to 39.0 ) after CA to reach a temperature ranging between $32^{\circ} \mathrm{C}$ and $34^{\circ} \mathrm{C}$ (see Figure 2). The hypothermia duration $\left(\mathrm{T}^{\circ} \geq 32\right.$ and $\leq 34^{\circ} \mathrm{C}$ ) was 21.0 hours in median (range: $7.0-31.0$ ). At the end of hospitalization, there are proportionally more patients having survived than deceased ones. Concerning the neurological status at the hospital discharge, few survivors present sequelea, mostly patients cooled tardily (see Figure 3).

Overall survival with and without hypothermia was 49/72 (68\%), with only 8 out of 49 patients presenting sequelae (16\%): three patients with cognitive disorders (time and space disorientation and confusion), one with short- and long-term memory disorders, three in coma, and one with a limited speech.

Patients who benefited from hypothermia had a survival rate of $72.7 \%$ (32/44), among which $81 \%$ without sequelae (26/32). Patients meeting the hypothermia's criteria but excluded because of their cardiopulmonary instability survive in one third of the cases.

Figure 3. Survival and neurological status at the discharge of the patients treated with hypothermia according to the hypothermia reaching time

Note. $\Delta \mathrm{H}$ : hypothermia temperatures
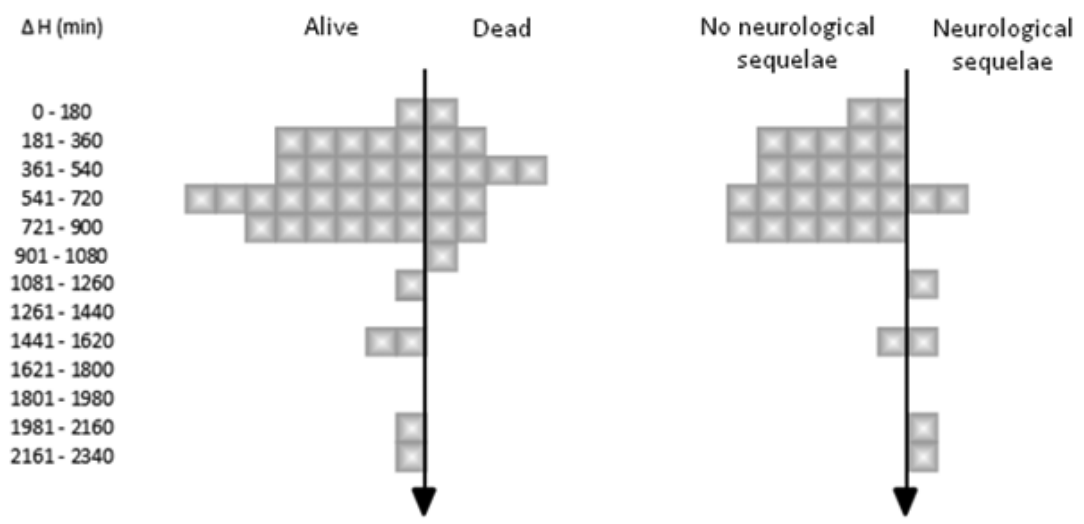
reaching time $\left(\leq 34^{\circ} \mathrm{C}\right)$

Finally, a color-coded representation of temperatures was added to observe their trends over the first 48 hours (see Figure 4). There was almost always a normothermic period of time before reaching $32^{\circ} \mathrm{C}-34^{\circ} \mathrm{C}$. Initially, hypothermia duration seemed similar among all the patients. It also appears that the frequency of hyperthermia was less important side of the year 2010. We also notice that several patients were already hypothermic at the time of the first temperature reading. These patients presented less neurological sequelae at the hospital discharge compared to the others $(85.7 \%$ versus $79.2 \%)$. Other patients presented pyrexia outside the protocol of cooling application period. Their survival rate is $75.8 \%$ and, among the survivors, the neurological outcome was good in $56 \%$ of the cases.

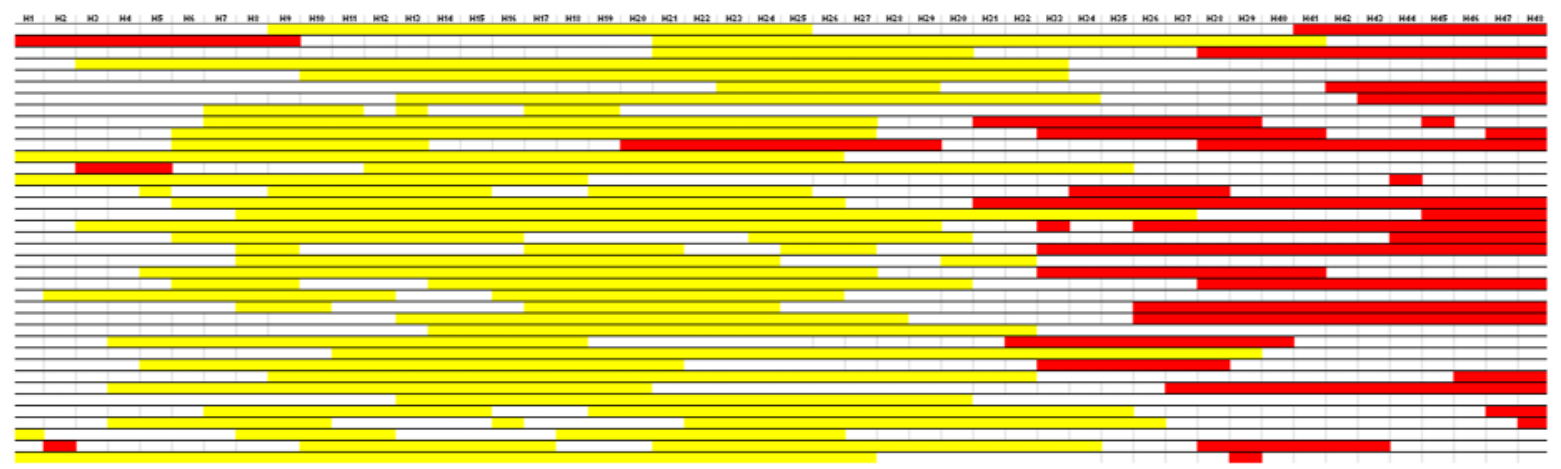

Figure 4. Coloured global temperatures among patients treated with hypothermia Note. White: normothermia $\left(>34^{\circ} \mathrm{C}\right.$ and $\left.\leq 37.6^{\circ} \mathrm{C}\right)$; Yellow: hypothermia $\left(\leq 34^{\circ} \mathrm{C}\right)$; Red: hyperthermia $\left(>37.6^{\circ} \mathrm{C}\right)$ 


\section{Discussion}

In our selected population, a survival rate of $72 \%$ was observed among patients treated with hypothermia. This rate is higher than those reported in earlier studies like Bernard et al. $(49 \%)^{[6]}$, the HACA study $\left(59 \%\right.$ at six months) ${ }^{[7]}$, and Laish-Farkash et al. $\left(63 \%{ }^{[8]}\right.$. At hospital discharge, $81 \%$ of the survivors did not have any neurologic sequelae. Again, at discharge, a better neurologic outcome than in previous studies is observed: $49 \%{ }^{[6]}, 55 \%$ at six months ${ }^{[7]}$, and $61 \%{ }^{[8]}$, respectively. Obviously, studied populations differ from each other as shown in Table 3. A logical explanation of these better results would be that time from collapse to goal temperature by good outcomes victims is shorter in our study, but that is not the case. Indeed the mean of this time is $593.38 \mathrm{~min} \pm 287 \mathrm{~min}$, and $538 \mathrm{~min} \pm 236.6$ in Laish-Farkash study ${ }^{[8]}$.

Table 3. Table comparing our study to three previous studies

\begin{tabular}{|c|c|c|c|c|}
\hline Characteristics & Our study & Laish-Farkash $^{[8]}$ & HACA $^{[7]}$ & Bernard $^{[6]}$ \\
\hline Type of study & $\begin{array}{l}\text { Retrospective, } \\
\text { without control } \\
\text { group }\end{array}$ & $\begin{array}{l}\text { Prospective, } \\
\text { without control } \\
\text { group }\end{array}$ & Prospective, with control group & $\begin{array}{l}\text { Prospective, } \\
\text { with control group }\end{array}$ \\
\hline $\begin{array}{l}\text { Number of } \\
\text { hypothermic } \\
\text { patients }\end{array}$ & 44 & 51 & 137 & 43 \\
\hline Age (years, range) & $18-91$ & $33-86$ & $51-69$ & $49-89$ \\
\hline Men $(\%)$ & 72 & 80 & 76 & 58 \\
\hline $\begin{array}{l}\text { CPR started by } \\
\text { bystander (\%) }\end{array}$ & 28 & 53 & 43 & 49 \\
\hline Survival (\%) & 72 & 63 & 59 at six months & 49 \\
\hline $\begin{array}{l}\text { Survived without } \\
\text { neurological } \\
\text { sequelae }(\%)\end{array}$ & 81 & 61 & 55 at six months & 49 \\
\hline Inclusion criteria & $\begin{array}{l}\text {-ROSC }{ }^{*} \text { after CA by } \\
\text { VF } \\
\text {-No answer to a } \\
\text { simple order at } \\
\text { arrival in emergency }\end{array}$ & $\begin{array}{l}\text {-ROSC }{ }^{*} \text { after CA } \\
\text { by VF } \\
\text {-Cardiac origin }\end{array}$ & $\begin{array}{l}\text {-ROSC }{ }^{*} \text { after CA by VF } \\
\text {-Cardiac origin } \\
\text {-Age: } 18 \text { to } 75 \text { ans } \\
\text {-Interval from } 5 \text { to } 15 \text { min between } \\
\text { CA and CPR by professionals } \\
\text {-Interval of less than } 60 \text { min } \\
\text { between -CA and ROSC }\end{array}$ & $\begin{array}{l}\text {-ROSC }{ }^{*} \text { after CA by } \\
\text { VF } \\
\text {-Persistant coma after } \\
\text { ROSC }^{*}\end{array}$ \\
\hline Exclusion criteria & $\begin{array}{l}\text {-Dying patients } \\
\text {-CA inducted by } \\
\text { cerebral hemorrhage } \\
\text {-Deep shock } \\
\text {-Severe hemorrhage } \\
\text {-Hemorrhagic shock } \\
\text {-Transferred patients } \\
\text {-NTBR } \\
\text {-Answer to verbal } \\
\text { order after-CPR } \\
\text {-No note in the } \\
\text { medical record }\end{array}$ & $\begin{array}{l}\text {-Pregnancy } \\
\text {-Terminal disease } \\
\text {-Cardiogenic } \\
\text { shock } \\
\text {-Life threatening } \\
\text { arythmia } \\
\text {-Known } \\
\text { preexistent } \\
\text { coagulopathy }\end{array}$ & $\begin{array}{l}\text {-Tympanic } \mathrm{T}^{\circ}<30^{\circ} \mathrm{C} \text { at admission } \\
\text {-Coma before } \mathrm{CA} \text { induced by drugs } \\
\text { depressing neurological system } \\
\text {-Pregnancy } \\
\text {-Answer to verbal order } \\
\text {-Arterial hypotension ( }<60 \mathrm{mmHg} \text { ) } \\
\text { during }>30 \text { min after } \mathrm{ROSC}^{*} \text { and } \\
\text { before randomization } \\
\text {-Hypoxemia ( }<85 \% \mathrm{O}_{2} \text { saturation) } \\
\text {-Participation in another study } \\
\text {-CA after arrival of medical team } \\
\text {-Known preexistent coagulopathy }\end{array}$ & $\begin{array}{l}\text {-Men }<18 \text { years } \\
\text {-Women }>50 \text { years } \\
\text { (possible pregnancy) } \\
\text {-Cardiogenic shock } \\
(<90 \mathrm{mmHg} \text { in spite of } \\
\text { epinephrin injection) } \\
\text {-Another causes of } \\
\text { coma: drug overdose, } \\
\text { trauma, ... }\end{array}$ \\
\hline
\end{tabular}

Note. ${ }^{*} \mathrm{ROSC}=$ return of spontaneous circulation

SPUH's hypothermia protocol was created in 2004 and, after several adaptations, became the present protocol. In our population, we noticed several misconducts in application of the protocol.

First, five patients not treated with hypothermia should have been cooled according to their neurological evaluation. For two of them, given reason is: ionic disorder and drug poisoning. For the three others, no reason is notified. Therefore, no 
valid cause for eluding hypothermia is reported leading to a $8.5 \%$ error rate. It is difficult to implement guidelines related to hypothermia in cardiac arrest. In 2008, a Resuscitation's editorial judged "suboptimal" the use of this therapy throughout the world ${ }^{[13]}$. Rittenberger et al. shows that it could be improved by a stepped cyclical process: in three years, the application rate of the protocol improves from $6 \%$ to $76 \%$ in out-of-hospital $\mathrm{CA}^{[14]}$. This demonstrated that, more the practitioners use the cooling, more efficiently they practice it and less patients are excluded. In our study, an error rate of $8.5 \%$ could be considered as acceptable.

Secondly, five patients are cooled whereas their neurological status in medical record don't require it. After discussion with senior ICU's doctors, it seems that this neurological evaluation in medical record don't always match with the true neurological status. This highlights the absence of neurological evaluation standardization between the emergency and the intensive care teams. A subjective evaluation alternates with a more objective evaluation like Glasgow Coma Scale (sometimes itself incomplete). On this point, considering the lack of a systematic precise neurological evaluation, either a neurologist's examination or a standardized neurological rating sheet would be useful. For instance, the ILCOR recommends the Cerebral Performance Category scale, although this scale is subject to an inter- and intra-reviewer variability ${ }^{[10,15]}$.

The recommended length of hypothermia is between $12-24$ hours ${ }^{[4,10]}$. The average time in our study is 21 hours in median. ICU of SPUH is thus fully effective for the maintenance of hypothermia during the required period of time. The delay between the CA and the deep of hypothermia is 9.5 hours in median. SPUH's hypothermia protocol indicates that the cooling must be started in the Emergency Department. However, there is no mention in the medical record of the place of initiation of hypothermia. Therefore, a question arises: could the delay to reach deep hypothermia be shorter? Animal models demonstrate that, earliest the hypothermia is initiated, the most beneficial effect is on neurological outcome. In human models, there are conflicting results: it seems that hypothermia remains beneficial even if delayed ${ }^{[16,17]}$. Therefore, there are still ongoing investigations to evaluate the effect of the delay of initiation of hypothermia in CA management. In 2010, transnasal evaporative cooling was studied in patients presenting with CA irrespective of rhythm ${ }^{[17,18]}$. It consisted in actively cooling the patient outside the hospital via a transnasal catheter which nebulized a cooling liquid with oxygen to the patient. Easy to use, the device reduced the body temperature of $-1.3^{\circ} \mathrm{C}$ (as compared with $-0.3^{\circ} \mathrm{C}$ in the control group) at hospital admission, and a therapeutic hypothermia was then obtained almost three times faster. This technique improved survival and neurological status in the patients in whom CPR was initiated within 10 minutes after the CA as compared with the control group with no pre-hospital cooling ${ }^{[17]}$. Therefore, it was concluded that it was an easy feasible way to initiate cooling. Concerning SPUH, the implementation of a common hypothermia protocol, to Emergency Medical Service (EMS), ED and ICU, would be useful in order to accelerate the body temperature decrease. Given the presence of regular refrigerators $\left(4^{\circ} \mathrm{C}\right)$ as well in the EMS intervention vehicles as in the ED, fluids (saline $0.9 \%$ or Hartmann's solutions) could be stored at $4^{\circ} \mathrm{C}$ for being at disposal of the medical staff. Then, temperature's decrease would be initiated by the EMS staff in the out-of-hospital setting and could be maintained during the medical transportation and treatment of the patient until the ICU admission. Ice bags could also contribute to the cooling.

Hyperthermia overshoot is observed in $75 \%$ of the patients after the hypothermia phase. In the literature, a thermal rise post-CA is frequently observed, but, unfortunately, few studies refer to the rise following a CA treated with hypothermia. In the first 48 hours after a $\mathrm{CA}$, the cerebral injury increases by a factor 2 for each degree above $37^{\circ} \mathrm{C}$, involving an increased risk of major neurologic disorders. The pyrexia could be caused by an infection, generally due to an inhalation bronchopneumonia during the initial comatose phase, but also could result from the brain injury at the hypothalamic level. The post-CA hyperthermia significance remains poorly understood. Since 2009, the SPUH's hypothermia protocol stipulates that an antipyretic treatment (medication or mechanical treatment) must be initiated as soon as the temperature exceeds $37^{\circ} \mathrm{C}$ after the end of the cooling. An antibiotic treatment could also be added in case of strong suspicion of infection. This point is in accordance with the guidelines recommending a gradual rewarming of the hypothermic patients $\left(0.25-0.5^{\circ} \mathrm{C}\right.$ per hour) and a treatment of pyrexia in the first $72 \mathrm{~h}$ post-CA ${ }^{[10,19-21]}$. 
A CPR was initiated by the bystanders before the EMS arrival in one third of our patients. An AED was also used out of the hospital in almost $90 \%$ of the cases. This highlights the bystander role over the three first links of the survival chain of Cummins ${ }^{[9]}$. Reanimation manoeuvers are simple and should be known by everyone. Moreover, since 2006, AEDs are at the disposal of the public under several conditions. They are placed in numerous public areas (railway stations, airports, shopping malls, ...). In this context, it is interesting to consider the general practitioners: they could inform and motivate the patients with flyers, available in the waiting room, summarizing the resuscitation first manoeuvers. Posters displays or information evenings or even training could also be included in their educational and preventive role. We could also encourage the uploading of software on smartphone dedicated to the "pocket CPR".

Finally, our study is a retrospective monocentric study with several biases. The studied group is made of patients taken in charge from the same area by only one hospital. Patient selection is done via the computer system in which the clinical record encoding could vary between individuals. The time recorded values does not reflect necessarily the exact time of the measurement: a variable written in the " 8 hour" column for example can be effectively recorded at 8:10 as well as at $8: 48$. This could result in biased calculated times. The selected patients are taken in charge by various practitioners with their own expertise, their own neurological evaluation and their own medical recording practice. The available notes are therefore not uniform and several data are missing or badly formulated. On this point, Nunnally et al. suggested the creation of a structured record for CA treated with hypothermia, distinct from the usual medical record. It would contain a pre-defined list of physiological well-known effects of hypothermia rated with scales. It would allow a complete uniform management, but also, an improved knowledge about the drugs dosages and the durations of the different treatments ${ }^{[22]}$. Lastly, due to the small sample size, no statistical inference could be made.

\section{Conclusion}

The management of CA with VF in SPUH appears to be effective in terms of survival and neurological protection. In order to optimize the management, we propose for the future to implement an ED - ICU common protocol and to create a specific CA registry. The latter could gather a large amount of information concerning patients with a CA and thus could provide an effective tool for the evaluation of the management of these individuals.

\section{List of abbreviations}

AED: Automatic External Defibrillator;

CA: Cardiac Arrest;

CPR: Cardiopulmonary Resuscitation;

CR: Cardiac Rhythm;

ED: Emergency Department;

EMS: Emergency Medical Service;

ICU: Intensive Care Unit;

ILCOR: International Liaison Committee on Resuscitation;

PEA: Pulseless Electrical Activity;

ROSC: Return of Spontaneous Circulation;

SPUH: Saint Pierre University Hospital;

VF: Ventricular Fibrillation

\section{Author's contributions}

Séverine Libert maked the conception and design of the study. She collected data and was involved in analysis and interpretation of the data. She wrote the initial draft of the manuscript.

Pierre Mols made substantial contributions to the conception, the design, and the interpretation of analyzes. He was involved in the critical review and gave the final approval before publication. 
Christian Mélot participated in the results analyzes and interpretation. He was involved in the critical review of the manuscript.

Philippe Dechamps collaborated to the collection of the data and gave their advice.

Marc Claus collaborated to the collection of the data and gave their advice.

Benoit Claessens collaborated to the collection of the data and gave their advice.

\section{Conflict of interests}

No conflict of interests was reported by the Authors.

\section{Announcement}

The paper has been published in French on Rev Med Brux (Rev Med Brux 2013; 34: 79-86), entitled "Etude rétrospective au sein du C.H.U. Saint-Pierre sur l'application de la recommandation d'hypothermie post arrêt cardiaque par fibrillation et tachycardie ventriculaire sans pouls".

\section{References}

[1] Gräsner JT, Herlitz J, Koster RW, Rosell-Ortiz F, Stamatakis L, Bossaert L. Quality management in resuscitation - Towards a European Cardiac Arrest Registry (EuReCa). Resuscitation. 2011; 82: 989-94. PMid: 21507548. http://dx.doi.org/10.1016/j.resuscitation.2011.02.047

[2] Claessens B, Jacques JM, Polikipis M, et al. The first hour quintet or the channel of care for the most usual urgent pathologies. Rev Med Brux. 2007; 28: 241-8. PMid: 17958016.

[3] Holmberg M, Holmberg S, Herlitz J. Effect of bystander cardiopulmonary resuscitation in out-of-hospital cardiac arrest patients in Sweden. Resuscitation. 2000; 47: 59-70. http://dx.doi.org/10.1016/S0300-9572(00)00199-4

[4] Nolan JP, Soar J, Zideman DA, et al. European Resuscitation Council Guidelines for Resuscitation 2010. Section 1. Executive summary. Resuscitation. 2010; 81: 1219-76. PMid: 20956052. http://dx.doi.org/10.1016/j.resuscitation.2010.08.021

[5] Mols P, Beaucarne E, Bruyninx J, et al. Early defibrillation by EMTs: the Brussels experience. Resuscitation. $1994 ; 27: 129-36$. http://dx.doi.org/10.1016/0300-9572(94)90005-1

[6] Bernard SA, Gray TW, Buist MD, et al. Treatment of comatose survivors of out-of-hospital cardiac arrest with induced hypothermia. N Engl J Med. 2002; 346: 557-63. PMid: 11856794. http://dx.doi.org/10.1056/NEJMoa003289

[7] The Hypothermia after Cardiac Arrest (HACA) Study Group: Mild therapeutic hypothermia to improve the neurologic outcome after cardiac arrest. N Engl J Med. 2002; 346: 549-56. PMid: 11856793. http://dx.doi.org/10.1056/NEJMoa012689

[8] Laish-Farkash A, Matetzky S, Kassem S, Haj-Iahia H, Hod H. Therapeutic hypothermia for comatose survivors after cardiac arrest. IMAJ. 2007; 9: 252-6. PMid: 17491216.

[9] Cummins RO, Ornato JP, Thies WH, Pepe PE. Improving survival from sudden cardiac arrest: the "chain of survival" concept. A statement for health professionals from the Advanced Cardiac Life Support Subcommittee and the Emergency Cardiac Care Committee, American Heart Association. Circulation. 1991; 83: 1832-47. PMid: 2022039. http://dx.doi.org/10.1161/01.CIR.83.5.1832

[10] Nolan JP, Neumar RW, Adrie C, et al. Post-cardiac arrest syndrome: epidemiology, pathophysiology, treatment, and prognostication. A Scientific Statement from the International Liaison Committee on Resuscitation; the American Heart Association Emergency Cardiovascular Care Committee; the Council on Cardiovascular Surgery and Anesthesia; the Council on Cardiopulmonary, Perioperative, and Critical Care; the Council on Clinical Cardiology; the Council on Stroke. Resuscitation. 2008; 79: 350-79. PMid: 18963350. http://dx.doi.org/10.1016/j.resuscitation.2008.09.017

[11] Arrich J, Holzer M, Havel C, Müllner M, Herkner H. Hypothermia for neuroprotection in adults after cardiopulmonary resuscitation. Cochrane Database Syst Rev. 2012 Sep 12; 9: CD004128. http://dx.doi.org/10.1002/14651858.CD004128.pub3

[12] Geocadin RG, Koenig MA, Jia X, Stevens RD, Peberdy MA. Management of brain injury after resuscitation from cardiac arrest. Neurol Clin. 2008; 26: 487-506. PMid: 18514823. http://dx.doi.org/10.1016/j.ncl.2008.03.015

[13] Acosta P, Varon J. Therapeutic hypothermia - From the bench to the bedside: are we there yet? Resuscitation. 2008 : 79; 183-4. PMid: 18951111. http://dx.doi.org/10.1016/j.resuscitation.2008.09.010

[14] Rittenberger JC, Guyette FX, Tisherman SA, DeVita MA, Alvarez RJ, Callaway CW. Outcomes of a hospital-wide plan to improve care of comatose survivors of cardiac arrest. Resuscitation. 2008: 79; 198-204. PMid: 18951113. http://dx.doi.org/10.1016/j.resuscitation.2008.08.014 
[15] Ajam K, Gold LS, Beck SS, Damon S, Phelps R, Rea TD. Reliability of the Cerebral Performance Category to classify neurological status among survivors of ventricular fibrillation arrest: a cohort study. Scand J Trauma Resusc Emerg Med. 2011; 19: 38. http://dx.doi.org/10.1186/1757-7241-19-38

[16] Walters JH, Morley PT, Nolan JP. The role of hypothermia in post-cardiac arrests patients with return of spontaneous circulation: a systematic review. Resuscitation. 2011: 82; 508-16. PMid: 21367510. http://dx.doi.org/10.1016/j.resuscitation.2011.01.021

[17] Castrén M, Nordberf P, Svensson L, et al. Intra-arrest transnasal evaporative cooling: a randomized, prehospital, multicenter study (PRINCE: Pre-ROSC IntraNasal Cooling Effectiveness). Circulation. 2010; 122: 729-36. PMid: 20679548. http://dx.doi.org/10.1161/CIRCULATIONAHA.109.931691

[18] Becker LB. Cooling heads and hearts versus cooling our heels. Circulation. 2010; 122: 679-81. PMid: 20679546. http://dx.doi.org/10.1161/CIRCULATIONAHA.110.968222

[19] Zeiner A, Holzer M, Sterz F, et al. Hyperthermia after cardiac arrest is associated with an unfavorable neurologic outcome. Arch Intern Med. 2001; 161: 2007-12. PMid: 11525703. http://dx.doi.org/10.1001/archinte.161.16.2007

[20] Takasu A, Saitoh D, Kaneko N, Sakamoto T, Okada Y. Hyperthermia: is it an ominous sign after cardiac arrest? Resuscitation. 2001; 49: 273-7. http://dx.doi.org/10.1016/S0300-9572(00)00360-9

[21] Takino M, Okada Y. Hyperthermia following cardiopulmonary resuscitation. Intensive Care Med. 1991; 17: 419-20. http://dx.doi.org/10.1007/BF01720680

[22] Nunnally ME, Jaeschke R, Bellingan GJ, et al. Targeted temperature management in critical care: a report and recommendations from five professional societies. Crit Care Med. 2011; 39: 1113-25. PMid: 21187745.

http://dx.doi.org/10.1097/CCM.0b013e318206bab2 